\title{
Quasi Natural Approach for Crystallization of Zeolites from Different Fly Ashes and Their Application as Adsorbent Media for Malachite Green Removal from Polluted Waters
}

\author{
Denitza Zgureva ${ }^{1, *(\mathbb{D})}$, Valeria Stoyanova ${ }^{2}$, Annie Shoumkova ${ }^{2}$, Silviya Boycheva ${ }^{3}[\mathbb{D}$ and \\ Georgi Avdeev ${ }^{2}$ \\ 1 College of Energy and Electronics, Technical University of Sofia, 8 Kl. Ohridsky Blvd, 1000 Sofia, Bulgaria \\ 2 Bulgarian Academy of Sciences, Institute of Physical Chemistry "R. Kaischew”, 1113 Sofia, Bulgaria; \\ valeriastoyanova@gmail.com (V.S.); anishu@abv.bg (A.S.); g_avdeev@ipc.bas.bg (G.A.) \\ 3 Department of Thermal and Nuclear Power Engineering, Technical University of Sofia, 8 Kl. Ohridsky Blvd, \\ 1000 Sofia, Bulgaria; sboycheva@tu-sofia.bg \\ * Correspondence: dzgureva@tu-sofia.bg
}

Received: 1 November 2020; Accepted: 20 November 2020; Published: 23 November 2020

check for updates

\begin{abstract}
Worldwide disposal of multi-tonnage solid waste from coal-burning thermal power plants (TPPs) creates serious environmental and economic problems, which necessitate the recovery of industrial waste in large quantities and at commercial prices. Fly ashes (FAs) and slag from seven Bulgarian TPPs have been successfully converted into valuable zeolite-like composites with various applications, including as adsorbents for capturing $\mathrm{CO}_{2}$ from gases and for removal of contaminants from water. The starting materials generated from different types of coal are characterized by a wide range of $\mathrm{SiO}_{2} / \mathrm{Al}_{2} \mathrm{O}_{3}$ ratio, heterogeneous structure and a complex chemical composition. The applied synthesis procedure resembles the formation of natural zeolites, as the raw FAs undergo long-term self-crystallization in an alkaline aqueous solution at ambient temperature. The phase and chemical composition, morphology and $\mathrm{N}_{2}$ adsorption of the final zeolite products were studied by scanning electron microscopy (SEM), energy-dispersive X-ray (EDX), X-Ray Diffraction (XRD) and Brunauer-Emmett-Teller (BET) analyses. The growth of faujasite (FAU) crystals as the main zeolite phase was established in all samples after 7 and 14 months of alkaline treatment. Phillipsite (PHI) crystals were also observed in several samples as an accompanying phase. The final products possess specific surface area over $400 \mathrm{~m}^{2} / \mathrm{g}$. The relationships between the surface properties of the investigated samples and the characteristics of the raw FAs were discussed. All of the obtained zeolite-like composites were able to remove the highly toxic dye (malachite green, MG) from water solutions with efficiency over $96 \%$. The experimental data were fitted with high correlation to the second-order kinetics.
\end{abstract}

Keywords: waste management; fly ash zeolites; faujasite; wastewater remediation

\section{Introduction}

In the recent years, one of the most current topics is related to the deteriorating quality of the environment, especially the purity of the atmospheric air and water basins. Their pollution is mainly due to anthropogenic factors and the intensive development of various industries. An illustrative example for this impact is the continuous increase in electricity consumption by both industry and households, and the necessity for greater energy production from power plants. According to the annual report of the International Energy Agency in 2018, the world gross electricity production was 
3.9\% higher than in 2017 [1]. Coal-fired thermal power plants (TPPs) still possess the largest share of the electricity market, $38 \%$ in 2018 . At the same time, coal combustion is the main contributor to the green house emission into the atmosphere and to the production of huge amounts of solid waste classified as hazardous in some countries [2,3]. The main challenge facing the industry today is to meet energy needs without having a negative impact on the environment. It could be expected that the future of the energy sector will be based on the combination of variety of energy sources with a key role of the traditional technologies, such as fossil fuel burning or nuclear fission, but at stricter environmental requirements [4]. In recent decades, the capture of carbon dioxide $\left(\mathrm{CO}_{2}\right)$ in TPPs has been intensively studied. At the beginning, the concept for liquefaction of $\mathrm{CO}_{2}$ and its further deposition in deep geological formation have been widely explored, referred to as carbon capture and storage (CCS). Lately, this approach was displaced by carbon capture and utilization (CCU), in which the captured $\mathrm{CO}_{2}$ is utilized in commercial products [5,6]. The CCS concept was gradually displaced by CCUS, which is carbon capture utilization and storage [7]. It could be expected that CCUS technologies will be commercialized soon and the requirements of the Paris Agreement to reduce $\mathrm{CO}_{2}$ emissions will be met in time for TPPs [8]. However, this does not apply to solid waste from the combustion of coal, which is produced as a by-product of the burning process. This residual consists of the mineral part from the fuel, which is incombustible. It could be obtained as slag or fly ash (FA) depending on the boiler design. Coal ash consists mainly of $\mathrm{SiO}_{2}, \mathrm{Al}_{2} \mathrm{O}_{3}, \mathrm{Fe}_{2} \mathrm{O}_{3}, \mathrm{CaO}, \mathrm{Na}_{2} \mathrm{O}$ and traces of other oxides. According to the World Wide Coal Combustion Products Network (WWCCCPN), the global annual ash production for 2016 is $1221.9 \mathrm{Mt}$ and almost a half is further utilized [9].

The most common approach for utilization of coal ash on an industrial scale is for production of constructional materials and cement. Based on their composition, FAs are classified in two classes $\mathrm{C}$ and $\mathrm{F}\left(50\right.$ wt. $\%<\mathrm{SiO}_{2}+\mathrm{Al}_{2} \mathrm{O}_{3}+\mathrm{Fe}_{2} \mathrm{O}_{3}<70$ wt. $\%$ for class $\mathrm{C}$ and $\mathrm{SiO}_{2}+\mathrm{Al}_{2} \mathrm{O}_{3}+\mathrm{Fe}_{2} \mathrm{O}_{3}>$ $70 \mathrm{wt}$. \% for class F) according to the ASTM C618. Class C fly ash can be used as a porland cement replacement due to its self-cementing and pozzolanic properties. Class $\mathrm{F}$ fly ash contains less $\mathrm{CaO}$ and higher amounts of glassy aluminosilicates and quartz, and it is used as a pozzolanic additive with less or without cementing values [10]. The unused part of the coal combustion wastes is stored in landfills, which leads to the destruction of agricultural land and creates a potential risk of ground water pollution. There are much published investigations on the opportunities for FA utilization but with limited applications on industrial scales mostly because of the cost ineffectiveness [11-13]. One promising approach for FA processing, first proposed in 1985, is the conversion of coal FA into zeolites due to their compositional similarities [14]. The most researched approach for synthesis of zeolites is the hydrothermal activation of FA in alkaline solution and a pilot installation for scale production is already in operation $[15,16]$. The biggest challenge facing this technique is the controlled production of a determined zeolite structure with well-defined properties, which predetermines the practical affordability of the material. Different zeolite structures or mixtures of them can be obtained depending on the chemical composition of the raw FA and mostly on the $\mathrm{SiO}_{2} / \mathrm{Al}_{2} \mathrm{O}_{3}$ ratio. For FA with a $\mathrm{SiO}_{2} / \mathrm{Al}_{2} \mathrm{O}_{3}$ ratio $<1.7$ at low molarity of $\mathrm{NaOH}(1-2 \mathrm{M})$ and an activation temperature in the region of $100-140{ }^{\circ} \mathrm{C}$ for a wide hydrothermal period from 2 to $96 \mathrm{~h}$, the dominant structure in the synthesized material is gismondine (GIS) [17-19]. At the same molarity of the $\mathrm{NaOH}$ activator, but with an increase in the temperature of $150-200{ }^{\circ} \mathrm{C}$, analacime (ANA) is obtained [17]. The lower synthesis temperature $\left(90^{\circ} \mathrm{C}\right)$ leads to the crystallization of a mixture of linde (LTA) and faujasite (FAU) zeolite structures in the final product [20]. For raw FA with $1.7<\mathrm{SiO}_{2} / \mathrm{Al}_{2} \mathrm{O}_{3}<2.4$, the tendency in the crystallization of zeolite structures by hydrothermal alkaline activation is the same as in the previous case. For these FAs, increasing the $\mathrm{NaOH}$ molarity from $1 \mathrm{M}$ to $2 \mathrm{M}$, the main GIS phase is replaced by phillipsite (PHI). A further increase in the molarity to 3.1-12.5 always leads to the crystallization of sodalite (SOD) [21,22]. Low quantities of LTA have been observed for these FAs at temperatures of $80-90{ }^{\circ} \mathrm{C}[22,23]$. For raw FA with $\mathrm{SiO}_{2} / \mathrm{Al}_{2} \mathrm{O}_{3}>2.4$, the main zeolite phases that crystallize at high activation temperatures $\left(140-150^{\circ} \mathrm{C}\right)$ and $3-4 \mathrm{M}$ of $\mathrm{NaOH}$ are $\mathrm{PHI}, \mathrm{SOD}$, and chabazite (CHA) [24]. At temperature of $60^{\circ} \mathrm{C}$ and $168 \mathrm{~h}$ of hydrothermal treatment, a negligible yield 
of FAU $<5$ wt. \% is obtained [25]. The two-stage synthesis has been developed by Shigemoto et al. in 1992. They introduced initial high temperature treatment of the mixtures of the raw FA and $\mathrm{NaOH}$ prior to the hydrothermal treatment [26-28]. In this step, soluble silica and alumina salts are produced, which facilitates the formation of hydrogel in water solution. The hydrogel then crystallizes onto unreacted parts of the FA particles, which act as crystallization centers. In this approach the raw FA composition does not affect the final zeolite structure, but the synthesis conditions are of key meaning. At high temperatures above $100{ }^{\circ} \mathrm{C}$ and $\mathrm{NaOH}$ molarity above 3, SOD is crystallized [29]. At activation temperatures below $100{ }^{\circ} \mathrm{C}$ and $2.0-2.5 \mathrm{M} \mathrm{NaOH}$, the resultant structure is LTA, while at molarity higher than $2.5 \mathrm{M} \mathrm{NaOH}$, the only crystalized zeolite is FAU [30,31].

FAU is a typical large pore zeolite with well-defined textural characteristics and easily accessible framework. These peculiarities make FAU suitable material for a wide range of applications mainly as an adsorbent, catalyst and ion exchanger. The fly ash zeolites (FAZ) of FAU type have been broadly studied for gas purification, soil recovery, heavy metal and radioactive species uptake, water softening, desalination and purification, including removal of dyes, microorganisms, and various organic and inorganic compounds [32,33]. In our previous studies, zeolite FAU obtained from lignite FA by two-stage synthesis was successfully applied as a $\mathrm{CO}_{2}$ adsorbent, catalyst for VOCs degradation, matrix for optical sensor, Fenton-like catalyst for removal of organic contaminants from water, adsorbent for retention of heavy metals and dyes from waste effluents [34]. The obtained results are promising but for applications on an industrial scale the two-stage synthesis would increase drastically the waste processing costs. The water remediation systems are intended for treatment of large water streams, which requires large amounts of the filtration materials.

In this study, we investigate the opportunity for a controlled obtaining of FAU-structured zeolite from raw fly ashes with a wide range of $\mathrm{SiO}_{2} / \mathrm{Al}_{2} \mathrm{O}_{3}$ ratios. The proposed synthesis approach resembles the formation of a natural zeolite as the raw FA undergoes self-crystallization in an alkaline water solution at ambient temperatures. Until recently, this technique was considered inappropriate due to the long crystallization time. However, the strategy of modern production is the development of a circular economy, which imposes the need to recover industrial waste in large quantities and at commercial prices. An advantage of recovering coal ash by zeolitization is that long-deposited ash can also be processed to repair already-caused environmental damages. The obtained FA zeolites are investigated in regard to their ability to remove dyes from contaminated water. The adsorption of malachite green (MG) is studied because of its high toxicity and presence in water used for fish farming. It has been established that MG remained in food could cause carcinogenesis, mutagenesis, chromosomal fractures, teratogenicity and respiratory toxicity [35].

\section{Materials and Methods}

\subsection{Materials}

The crystallization of zeolites was investigated for raw FAs sampled from seven different sources obtained by combustion of lignite, brown, and anthracite coal in Bulgarian thermal power plants (TPPs). Five of the raw samples are fine powders collected from the electrostatic precipitators of TPPs, one is a solid slag sampled from bottom ash, and another one is a mixture of FA with slag. Prior to the synthesis, the slag was screened to obtain a fraction with particle sizes smaller than $0.2 \mathrm{~mm}$. Detailed analyses of the raw materials were reported in our previous studies, where mainly amorphous aluminosilicates and crystalline phases of quartz, gypsum, mullite, and magnetite were detected [36,37]. The chemical composition of $\mathrm{FAs}, \mathrm{SiO}_{2} / \mathrm{Al}_{2} \mathrm{O}_{3}$ ratios, the $\mathrm{FA}$ classification and the weight part of the amorphous ingredients calculated by integral deconvolution of XRD spectra of analyzed samples (uncertainty of $\pm 2.5 \%$ ) are summarized in Table 1 . 
Table 1. Chemical composition and amorphous part of fly ashes (FAs) subjected to zeolitization.

\begin{tabular}{|c|c|c|c|c|c|c|c|c|c|c|c|c|}
\hline $\begin{array}{l}\text { Raw } \\
\text { FA }^{1}\end{array}$ & $\begin{array}{c}\mathrm{SiO}_{2} \\
\text { wt. \% }\end{array}$ & $\begin{array}{l}\mathrm{Al}_{2} \mathrm{O}_{3} \\
\text { wt. \% }\end{array}$ & $\begin{array}{l}\mathrm{Fe}_{2} \mathrm{O}_{3} \\
\text { wt. \% }\end{array}$ & $\begin{array}{l}\mathrm{Na}_{2} \mathrm{O} \\
\text { wt. \% }\end{array}$ & $\begin{array}{c}\mathrm{CaO} \\
\text { wt. \% }\end{array}$ & $\begin{array}{l}\mathrm{MgO} \\
\text { wt. \% }\end{array}$ & $\begin{array}{c}\mathrm{SO}_{3} \\
\text { wt. \% }\end{array}$ & $\begin{array}{c}\mathrm{K}_{2} \mathrm{O} \\
\text { wt. \% }\end{array}$ & $\begin{array}{c}\mathrm{TiO}_{2} \\
\text { wt. \% }\end{array}$ & $\begin{array}{c}\mathrm{SiO}_{2} / \mathrm{Al}_{2} \mathrm{O}_{3} \\
\text { wt. ratio }\end{array}$ & $\begin{array}{c}\text { FA } \\
\text { Class }\end{array}$ & $\begin{array}{c}\text { AP }^{2} \\
\text { wt. \% }\end{array}$ \\
\hline FAB & 40.29 & 20.49 & 13.59 & 0.79 & 13.11 & 2.14 & 3.21 & 4.09 & 2.30 & 1.97 & F & 58 \\
\hline FAG & 12.50 & 8.36 & 45.87 & 0.65 & 6.42 & 0.49 & 25.72 & 0.00 & 0.00 & 1.50 & C & 36 \\
\hline FAM & 39.51 & 22.89 & 16.09 & 1.78 & 9.88 & 2.58 & 5.34 & 1.34 & 0.59 & 1.73 & $\mathrm{~F}$ & 57 \\
\hline FAR & 54.63 & 28.67 & 5.94 & 0.00 & 1.53 & 1.94 & 1.08 & 4.87 & 1.35 & 1.91 & $\mathrm{~F}$ & 54 \\
\hline FARE & 49.30 & 27.02 & 14.40 & 0.00 & 3.23 & 2.08 & 0.00 & 3.98 & 0.00 & 1.82 & $\mathrm{~F}$ & 94 \\
\hline FAV & 46.75 & 27.13 & 10.31 & 1.08 & 3.73 & 1.55 & 2.99 & 6.46 & 0.00 & 1.72 & F & 65 \\
\hline SS & 39.47 & 17.17 & 20.09 & 1.11 & 10.72 & 1.55 & 5.94 & 3.95 & 0.00 & 2.30 & $\mathrm{~F}$ & 100 \\
\hline
\end{tabular}

${ }^{1}$ FAB (FA from TPP "Bobovdol", 630 MW, brown coals with high ash content); FAG (from TPP "AES Galabovo", 670 MW, lignite coals); FAM (FA from TPP "Maritza 3", 900 MW, lignite coals); FAR (from TPP "Republika", 180 MW, brown coals); FARE (FA mixed with grinded in a planetary ball mill slag from TPP "Rousse East", 400 MW); FAV (FA from TPP "Varna", 1260 MW, highly calorific and low sulphur anthracite coals); SS (slag from TPP "Sviloza", Svishtov, $120 \mathrm{MW}$, bituminous coals). ${ }^{2} \mathrm{AP}$ is the amorphous part in the samples calculated by deconvolution of the XRD spectra.

\subsection{Aging Method}

The self-crystallization is performed as $10 \mathrm{~g}$ FA was added to $150 \mathrm{~mL} 5 \mathrm{M} \mathrm{NaOH}$ (purity $>98 \%$, Valerus, Sofia, Bulgaria), the slurries were filled in closed reaction vessels and stayed for aging at ambient temperature. The mixtures were stirred for homogenization over long time intervals. A small portion of the samples was taken out from the vessels after 7 and 14 months, washed with distilled water until $\mathrm{pH}=8$ and dried at room temperature. The synthesized samples were named with prefix Z-zeolite before FA acronyms, followed by dash and time of the conversion. The powdered products were subjected to various analyses in order to evaluate their structure, morphology, and surface properties.

\subsection{XRD Analysis}

X-ray diffractograms of the all samples were measured on a Philips PW 1050 powder diffractometer with $\mathrm{CuK} \alpha$ filtered radiation and Bragg-Brentano geometry in the diffraction angle range $2 \theta$ from 6 to $84.95^{\circ}$ at a step width of $0.05^{\circ}(2 \theta)$ for scan time of $1 \mathrm{~s}$. An equal mass of powdered samples and identical sample holders was used in all XRD measurements. The identification of all crystalline phases was performed by the X'Pert HighScore 3.0d software (2011 PANalytical B.V., The Netherlands) and the database of X-ray patterns collection of the International Zeolite Association.

\subsection{SEM and EDX Analysis}

The morphology and the integral chemical composition of the samples were studied by scanning electron microscopy (SEM) on a JSM6390 apparatus, equipped with an Oxford Instruments EDX analyzer (Highcombe, London, UK). The sample images were investigated in both secondary electron imaging (SEI) and backscattered electron imaging (BEI) modes. SEI images provided by secondary electrons originated from the surface or the near-surface regions of the samples give information for the morphology, size and surface topography of the objects. Micrographs in BEI mode are derived by the backscattered electrons detected out of the specimen interaction volume, which are proportional to the atomic number of the attended chemical elements. As a result, the objects rich in heavy metals look brightly shining on the dark background of the other particles (alumosilicates, calcites, etc.). All energy-dispersive X-ray analyses (EDX) were performed at $20 \mathrm{keV}$. Elements with an atomic number less than that of nitrogen are not included in the determination of the elements weight percentage (wt. \%). The average composition of the samples was estimated on the base of so-called "integral spectra" taken at low magnification $(\sim 30 \times)$ from an area comprising several hundred to thousand particles, scanned for at least $300 \mathrm{~s}$. The elemental spectrum of single particles was determined using "in point" analysis at substantially higher magnifications $(\sim 1000-300,000 \times)$, recorded for about $60 \mathrm{~s}$.

\subsection{Nitrogen Adsorption/Desorption Tests}

The studies on the surface properties of all samples were performed with $\mathrm{N}_{2}$-adsorption/desorption analysis by a volumetric gas analyzer Micromeritics TriStar 3020 (Micromeritics Instrument Corp., 
Norcross, GA, USA), according to the ISO 9277:2010 standard [38]. The samples were pretreated at $260{ }^{\circ} \mathrm{C}$ for $4 \mathrm{~h}$ under continuous Helium flow to release moisture and atmospheric gases. The samples were further degassed by evacuation with a rate of $0.67 \mathrm{kPa} / \mathrm{s}$ for $1 \mathrm{~h}$ provided by an Edwards vacuum pump. The isotherms were built using $\mathrm{N}_{2}$ gas of analytical purity $(5 \mathrm{~N})$ at cryogenic temperature of $77 \mathrm{~K}$ provided by liquid nitrogen. The adsorption/desorption tests were performed at 92 experimental points in the pressure range $\mathrm{p} / \mathrm{p}_{0}=0.001-0.995$, where $\mathrm{p}_{0}$ is the saturation pressure depending on the ambient temperature (approximately $104 \mathrm{kPa}$ ). To the experimental isotherms, standardized Brunauer-Emmett-Teller (BET), t-plot and Barrett-Joyner-Helenda (BJH) models were applied for calculation of specific surface area (SSA, $\left.\mathrm{m}^{2} / \mathrm{g}\right)$, micropore area $\left(\mathrm{S}_{\text {micro }}, \mathrm{m}^{2} / \mathrm{g}\right)$, external surface area $\left(\mathrm{S}_{\text {external }}, \mathrm{m}^{2} / \mathrm{g}\right)$, micropore volume $\left(\mathrm{V}_{\text {micro }}, \mathrm{cm}^{3} / \mathrm{g}\right)$, mesopore volume $\left(\mathrm{V}_{\text {meso }}, \mathrm{cm}^{3} / \mathrm{g}\right)$, and average pore width $(\AA)$. The relative pressure range of the monolayer adsorption for application of the BET model was calculated from the extreme value of the function $n_{a} \cdot\left(1-p / p_{0}\right)=f\left(p / p_{0}\right)\left(n_{a}\right.$ is quantity of $N_{2}$ adsorbed, $\mathrm{mmol} / \mathrm{g})$.

\subsection{Dye Adsorption}

The adsorption tests were performed in $100 \mathrm{~mL}$ water solution of MG (96\% of purity, Valerus, Sofia, Bulgaria) with stock concentration of $10 \mathrm{~mL} / \mathrm{l}$ by immersing of $5 \mathrm{~g}$ fly ash zeolites obtained after 14 months of crystallization (FAZs-14). The adsorption kinetics was studied by measuring MG concentration by the help of UV spectrophotometer, 1200 Series, Cole Palmer Instruments Company, East Bunker Court, IL, USA. Various kinetic models were applied to the experimental data to evaluate the parameters of the water purification process.

\section{Results and Discussions}

\subsection{Phase Composition of the Coal Fly Ash Zeolites}

The results from XRD analyses are plotted in Figure 1, presenting the patterns of the raw FAs, synthesized products after 7 and 14 months, and referent zeolite FAU for comparison. The most intensive reflexes of FAU could be found in all FAZs, and at $2 \theta \approx 26.6^{\circ}$ the zeolite peak overlaps with that of the quartz transferred into the products from the raw FA. Thus, the presence of unreacted quartz could not be confirmed unambiguously by XRD analysis, but it could be assumed when expansion or splitting of the peak characteristic of both phases is observed. Only at XRD patterns of FAZs obtained from completely amorphous raw fly ashes, such as SS and FARE, it can be considered undoubtedly that the intensive peak at this angle belongs to FAU. For samples of the all series, the longer synthesis time leads to a slight increase in the intensity of the reflexes. At the zeolite obtained from FAB after 14 months of alkaline aging, a mixture of zeolite structures is observed, as, in addition to FAU reflexes, two intensive peaks of PHI are identified on its patterns. A single PHI reflex is also appeared at the XRD spectra of the samples synthesized from FAR and FAV. On their XRD patterns, a shoulder at the base of the peak assigned to FAU could be also seen, which is indicative for incomplete assimilation of the quartz in the zeolitization process. For the samples aged 14 months, the shoulder is more pronounced as compared to FAZs obtained under shorter time of incubation. This indicates that, due to its thermodynamic instability, FAU begins to recrystallize after prolonged incubation in the reaction mixture. Considering that the same amounts of all samples are subjected of XRD analysis, it could be supposed that maximum yield of zeolite FAU is obtained at FAZs from the series FAR, FARE, and FAV because their patterns are characterized by the largest total areas described by FAU peaks.

\subsection{Morphological Study of Coal Fly Ash Zeolites}

More detailed studies on the crystallization of zeolites from FA were achieved by performing the morphological SEM analysis of the obtained samples. The results for the samples originated from FAB, FAG, and FAM are shown in Figure 2, while for those from FAR, FARE, FAV, and SS are presented in Figure 3. The SEM images of ZFAB-7 (zeolite from FAB obtained after 7 months of exposure) show the 
presence of single FAU crystals with average diameter of $3.5 \mu \mathrm{m}$ and agglomerates of smaller FAU particles $(1 \mu \mathrm{m})$. On the second image of the same sample, crystals with prismatic morphology typical for zeolite PHI are also observed. The longer synthesis time leads to intensive growth of PHI crystals which corresponds to an increase in the intensity of the peaks of this zeolite phase on the XRD pattern of the sample ZFAB-14.

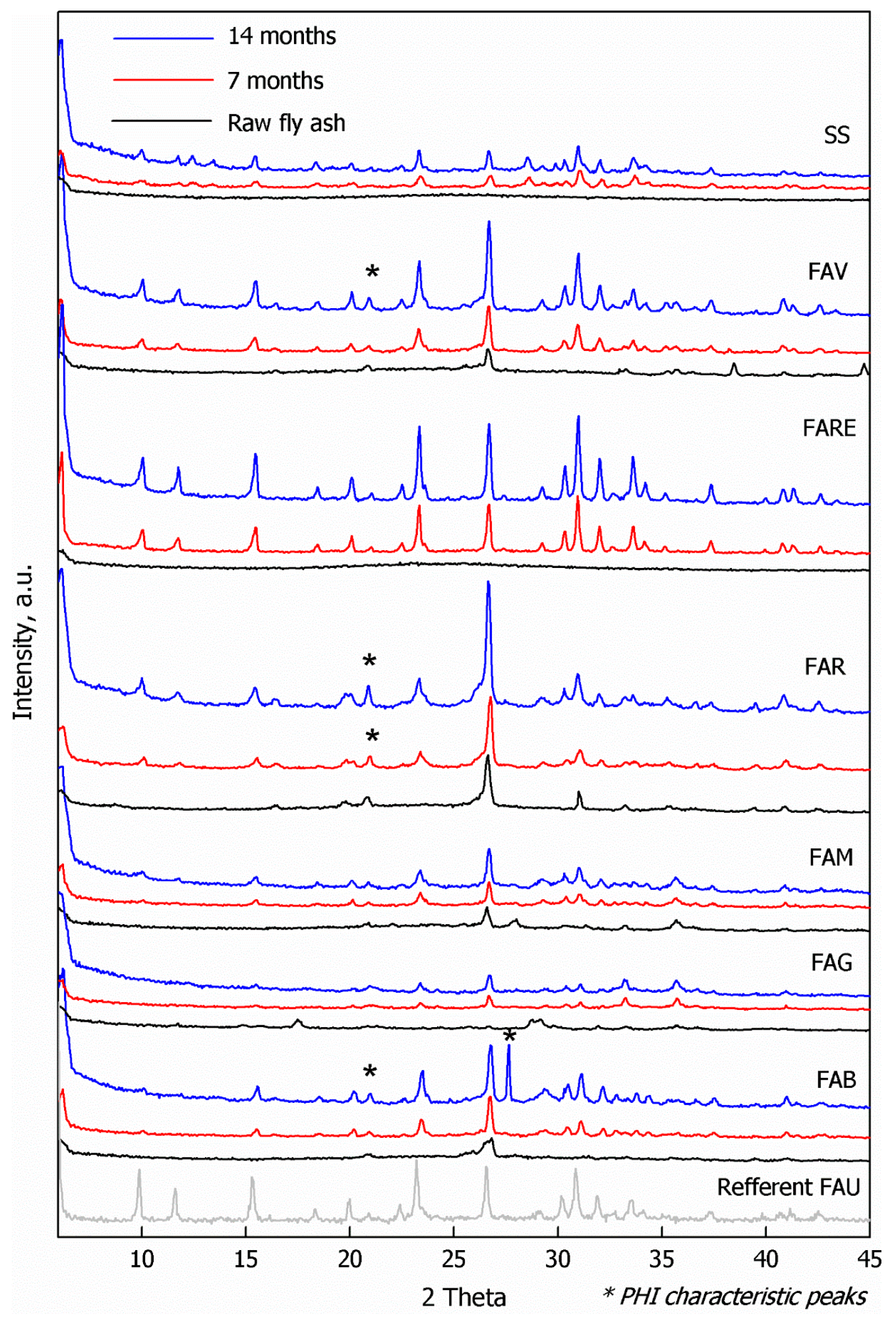

Figure 1. X-ray diffraction patterns of raw fly ashes and synthesized samples after 7 months (red spectra) and 14 months (blue spectra) of quasi-natural crystallization. 

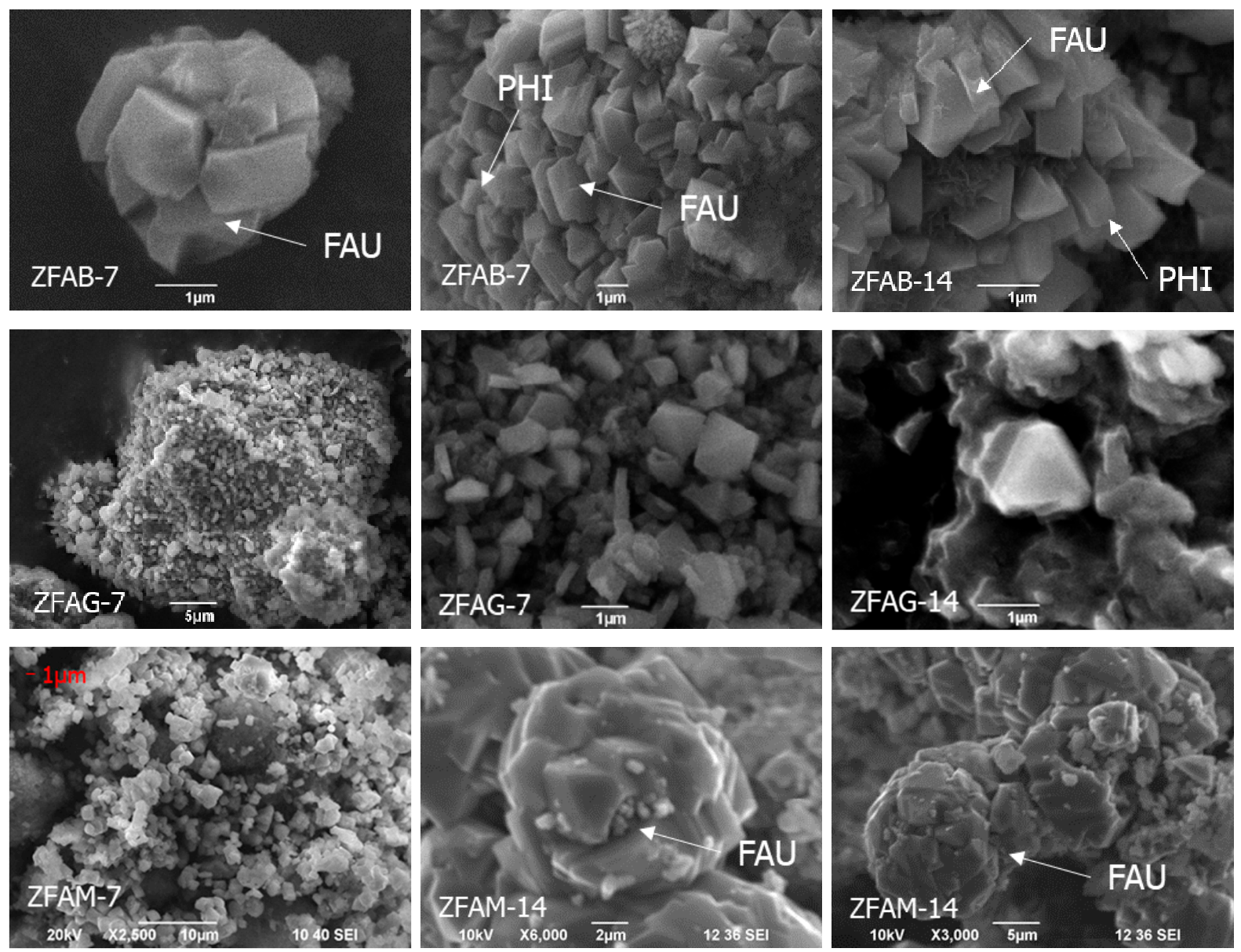

Figure 2. Scanning electron microscopy (SEM) images of fly ash zeolites obtained from FAB, FAG, and FAM after 7 and 14 months of crystallization.

On the SEM images of the materials synthesized from FAG, typical FAU crystals could also be identified but in a strong morphological disorder. The first image of ZFAG-7 shows the crystallization of new structures onto particles of irregular shape probably remnants of unreacted fly ash. The images with higher magnification indicate the presence of disordered FAU crystals with sizes ranging from 0.1 to $1.5 \mu \mathrm{m}$. Prolongation of the reaction time does not lead to a substantial change in the morphology of the sample (ZFAG-14). The morphology analyses of samples derived from FAM show intensive crystallization of FAU, as submicron individual crystals were obtained after 7 months of reaction, as it is revealed by the SEM image of ZFAM-7. The doubling of the reaction time leads to an increase in the diameters of the individual crystals, and to their agglomeration, as it is observed in the images of ZFAM-14.

The SEM images of the ZFAR-7 sample correspond very well to the XRD data, as the simultaneous presence of FAU and PHI crystals is observed at a shorter synthesis time. The crystallization of zeolite structures occurs over unreacted FA particles, which act as crystallization centers and this could be observed in the SEM micrograph of ZFAR-14. Unlike previous samples, SEM analyses of the FARE series indicate FAU crystallization from FA with homogeneous distribution of the individual crystals by their size. Similar morphology with respect to the crystalline shape is observed for the sample obtained from FAV after 7 months of synthesis, but the size of the individual particles is almost twice lower. The SEM image of ZFAV-14 confirms the observation on the XRD pattern of the same sample, as prismatic crystals of PHI grow among the FAU structure. At the sample ZFAB-7, the crystallization of $\mathrm{PHI}$ is related to the XRD peak at $2 \theta \approx 20.9$, while at ZFAB-14 the growth of PHI crystals is associated to the intensive peak at $2 \theta \approx 27.6$, which is the most pronounced reflex for the pure phase. At the 
series of samples obtained from SS, the presence mainly of the FAU structure is also confirmed, as for a shorter time of 7 months the crystals are well-shaped with sizes of 5-7 $\mu \mathrm{m}$. However, the prolongation of the reaction leads to agglomeration and to obtaining of dense aggregates of particles.
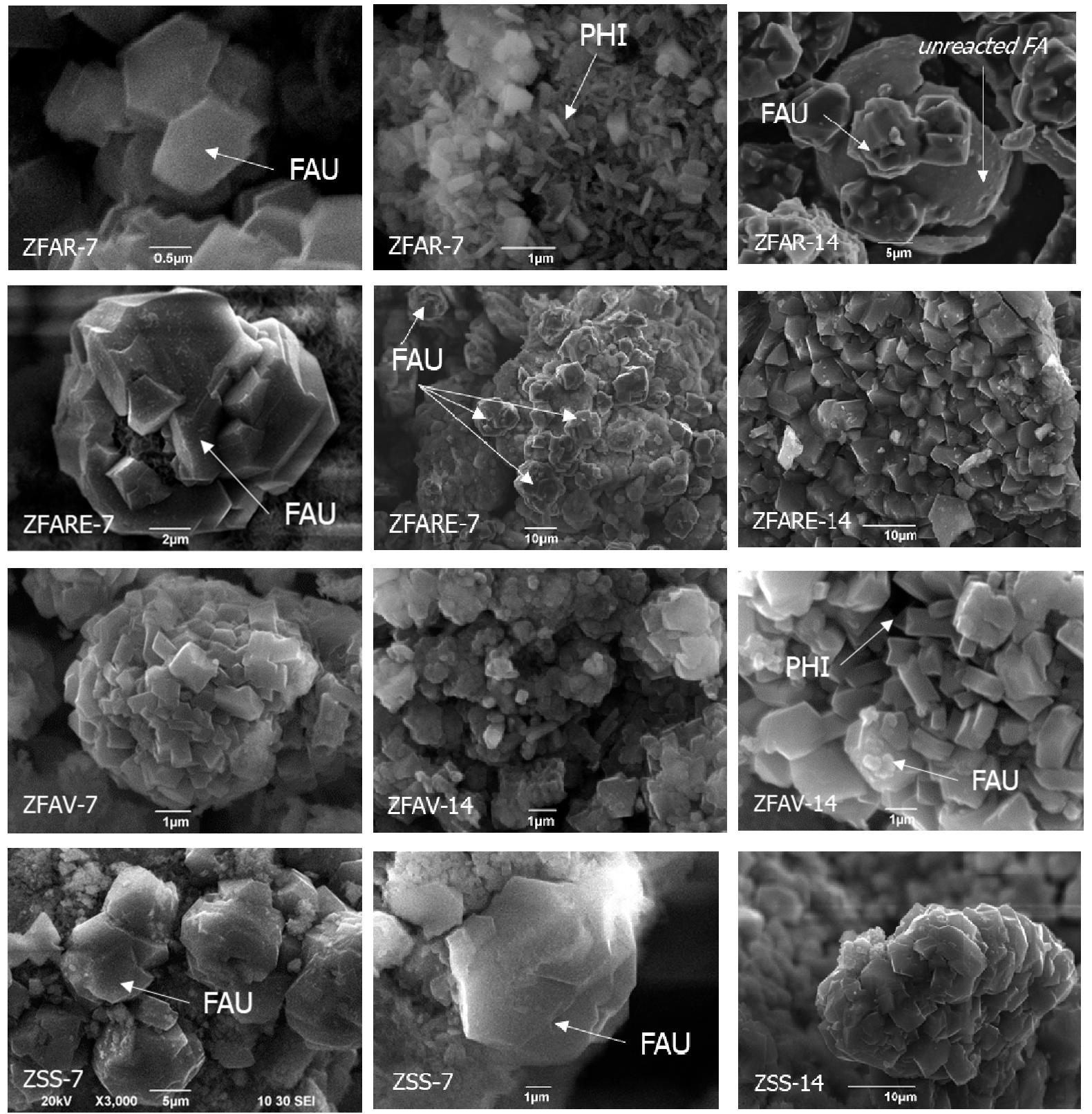

Figure 3. SEM images of fly ash zeolites obtained by FAR, FARE, FAV and SS after 7 and 14 months of crystallization.

\subsection{Surface Properties of Coal Fly Ash Zeolites}

The isotherms of $\mathrm{N}_{2}$-adsorption/desorption for the raw FAs and FAZs of different raw materials converted for 7 and 14 months are plotted in Figure 4. The raw FAs are characterized by weak $\mathrm{N}_{2}$ adsorption and isotherms of Type III corresponding to non-porous materials, as it is demonstrated for FAR and FAM (Figure 4). The isotherms of all FAZs refer to Type IV according to the International Union of Pure and Applied Chemistry (IUPAC) classification, and their shape is typical for porous solids with mixed micro-mesoporosity. At all plots, fast adsorption at low pressure range $\mathrm{p} / \mathrm{p}_{0}=0.001-0.05$ is observed due to the micropores filling and monolayer formation. The part of the isotherms at $\mathrm{p} / \mathrm{p}_{0}=0.05-0.85$ corresponds to the multilayer adsorption of molecules and the filling of mesopores. 
The different slope of this region determines the share of mesopores into the structure. The region of the adsorption isotherms at $\mathrm{p} / \mathrm{p}_{0}=0.85-0.99$ represents the filling in macropores or gas adsorption in the inter-particles free volume of the powdered material. The desorption branches go above the adsorption isotherms, describing hysteresis loops which are closed at $\mathrm{p} / \mathrm{p}_{0}=0.45$ for all samples. The type of all hysteresis loops is $\mathrm{H} 3$, which corresponds to parallel plate-shaped pores with different widths, depending on the hysteresis area [39]. The most intensive monolayer filling is observed for samples from series FAV and FARE, as the quantity of the adsorbed gas reaches $4.3 \mathrm{mmol} / \mathrm{g}$ at $\mathrm{p} / \mathrm{p}_{0}=0.025$, and their specific surface area is expected to be the highest. The sample ZFAV-14 possesses higher adsorption in the low pressure region as compared to ZFAV-7, which could be explained by the higher yield of zeolite FAU after a longer time of synthesis. The other sample sets follow the same trend with some exceptions, mostly for the ZSS series. ZSS-14 obtained after 14 months of crystallization has weak adsorption, which is not typical for zeolite FAU. This could be explained by the degradation of the crystallized FAU after its longer incubation into the alkaline solution. Zeolite FAU is obtained as a metastable phase and, upon prolonged alkaline treatment, it recrystallizes to a more stable zeolite phase, but with a lower surface area. Similar observations have been made in our previous studies on self-crystallization of FA investigating the influence of the reaction mixture alkalinity on the final product [11]. The raw fly ash SS is highly amorphous, which predetermines faster kinetics of its alkaline conversion. Most likely, the crystallization of FAU from SS has reached the maximum rate at a shorter reaction time and further incubation of the product in the alkaline solution is led to the destruction of FAU.

The data from $\mathrm{N}_{2}$ isotherms of FAZs are processed by different mathematical models to calculate their surface characteristics. The determined surface properties of FAZs are listed in Table 2.

Table 2. Surface properties of FAZs calculated by the $\mathrm{N}_{2}$-adsorption/desorption experimental isotherms.

\begin{tabular}{ccccccccc}
\hline Sample & $\begin{array}{c}\text { SSA } \\
\mathbf{m}^{\mathbf{2}} \mathbf{g}\end{array}$ & $\begin{array}{c}\mathbf{S}_{\text {micro }} \\
\mathbf{m}^{\mathbf{2}} \mathbf{g}\end{array}$ & $\begin{array}{c}\mathbf{S}_{\text {external }} \\
\mathbf{m}^{2} / \mathbf{g}\end{array}$ & $\begin{array}{c}\mathbf{V}_{\text {micro }} \\
\mathbf{c m}^{\mathbf{3}} / \mathbf{g}\end{array}$ & $\begin{array}{c}\mathbf{V}_{\text {meso }} \\
\mathbf{c m}^{\mathbf{3}} \mathbf{g}\end{array}$ & $\begin{array}{c}\mathbf{V}_{\text {total }} \\
\mathbf{c m}^{\mathbf{3}} \mathbf{g}\end{array}$ & $\begin{array}{c}\mathbf{W}_{\text {pores }} \\
\mathbf{A}\end{array}$ & $\begin{array}{c}\mathbf{M}_{\text {share }} \\
\mathbf{\%}\end{array}$ \\
\hline ZFAB-7 & 296 & 210 & 86 & 0.0834 & 0.1755 & 0.2589 & 65.55 & 32 \\
ZFAB-14 & 282 & 201 & 81 & 0.0801 & 0.1607 & 0.2407 & 64.60 & 33 \\
ZFAG-7 & 123 & 37 & 86 & 0.0154 & 0.1275 & 0.1429 & 50.47 & 11 \\
ZFAG-14 & 139 & 43 & 96 & 0.0176 & 0.1241 & 0.1417 & 46.25 & 12 \\
ZFAM-7 & 224 & 140 & 84 & 0.0568 & 0.1862 & 0.2430 & 63.65 & 23 \\
ZFAM-14 & 210 & 133 & 77 & 0.0539 & 0.1669 & 0.2209 & 61.41 & 24 \\
ZFAR-7 & 238 & 174 & 64 & 0.0684 & 0.1338 & 0.2022 & 68.46 & 34 \\
ZFAR-14 & 248 & 182 & 66 & 0.0717 & 0.1264 & 0.1981 & 63.48 & 36 \\
ZFARE-7 & 404 & 357 & 47 & 0.1344 & 0.0742 & 0.2086 & 48.51 & 64 \\
ZFARE-14 & 389 & 339 & 50 & 0.1279 & 0.0867 & 0.2147 & 51.97 & 60 \\
ZFAV-7 & 341 & 275 & 66 & 0.1050 & 0.1196 & 0.2247 & 65.14 & 47 \\
ZFAV-14 & 387 & 319 & 68 & 0.1222 & 0.1190 & 0.2412 & 62.22 & 51 \\
ZSS-7 & 169 & 131 & 38 & 0.0502 & 0.0687 & 0.1189 & 67.68 & 42 \\
ZSS-14 & 43 & 13 & 30 & 0.0057 & 0.0588 & 0.0646 & 67.00 & 9 \\
\hline
\end{tabular}

Note SSA-specific surface area, $\mathrm{S}_{\text {micro }}$-micropore area, $\mathrm{S}_{\text {external }}$-external surface area, $\mathrm{V}_{\text {micro }}$-micropore volume, $\mathrm{V}_{\text {meso }}$ - mesopore volume, $\mathrm{V}_{\text {total }}$-total pore volume, $\mathrm{W}_{\text {pores }}$-average pore width, $\mathrm{M}_{\text {share }}$-volume share of micropores.

Although, the zeolite FAU was identified by XRD and SEM at the all synthesized samples, FAZs differ in their textural properties. The specific surface area of the samples varies in a wide range as the highest obtained value is $404 \mathrm{~m}^{2} / \mathrm{g}$ for the sample ZFARE-7. Slight decrease in SSA and in the share of micropores is obtained for longer time of synthesis at ZFARE-14, which could be indicative for the beginning of recrystallization process. The SSAs of the samples of ZFAV series are comparable, as the yield of zeolite FAU remains high after 14 months of reaction. The volume fraction of micropores for ZFAVs is relatively lower than that for ZFAREs, because of the different amorphous part in the structure of the raw materials. Similar textural properties are calculated for the samples from the series ZFAB, ZFAM, and ZFAR with SSAs in the range of $210-296 \mathrm{~m}^{2} / \mathrm{g}$. Despite the lower 
surface area compared to the previous series of samples, the total pore volume of these FAZs is higher, reaching values of $0.2589 \mathrm{~cm}^{3} / \mathrm{g}$ due to the wider pores with sizes up to $68.46 \AA$. The well-developed mesopore structure of these materials is beneficial for their application in systems for adsorption of gases or for removal of pollutants from waters. The lowest values for all surface characteristics are calculated for the samples from the ZFAG and ZSS series, which is in accordance to the observation from $\mathrm{XRD}, \mathrm{SEM}$, and $\mathrm{N}_{2}$-adsorption analyses.
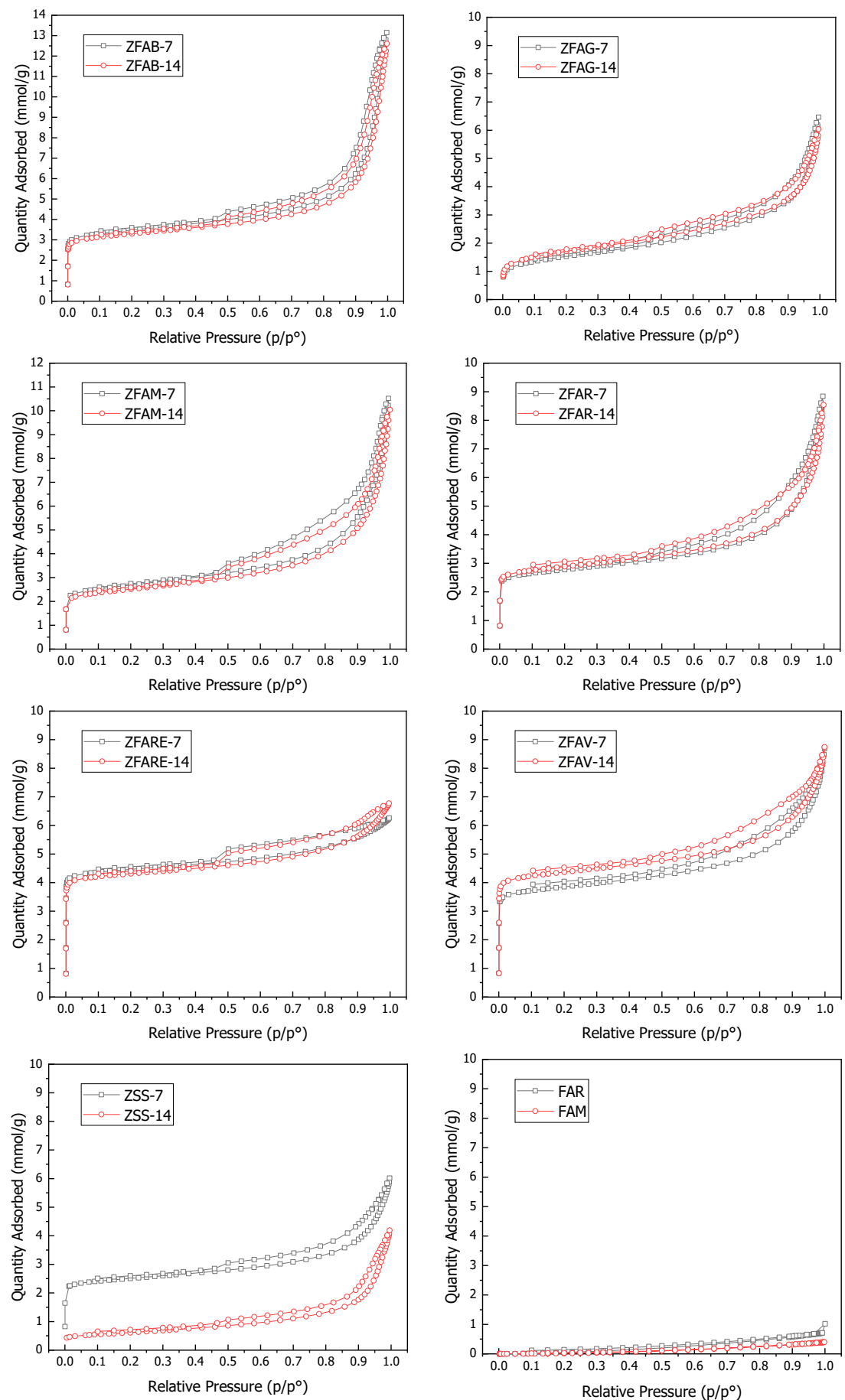

Figure 4. Isotherms of $\mathrm{N}_{2}$-adsorption/desorption of FAs and FAZs obtained from different raw materials for 7 and 14 months. 
There is no unified approach to estimate the zeolitic yield in the products of FA conversion. In the literature, data from thermogravimetric analyses, water vapor adsorption and release, XRD deconvolution, and SSA comparison have been applied for the estimation of the zeolitization extent [40]. In this study, the SSA of the synthesized samples was used to evaluate the influence of the raw fly ashes properties onto the crystallization of zeolite FAU. The dependences of SSAs and $\mathrm{M}_{\text {share }}$ of the investigated samples (excluding SS because of the FAU destruction observed) on the $\mathrm{SiO}_{2} / \mathrm{Al}_{2} \mathrm{O}_{3}$ ratio and the amorphous constituent of FA are represented in Figure 5. The increase in SSA and the yield of zeolite FAU are directly related to the enhancement of the amorphous content in the raw fly ash. The same dependence is observed for the micropores share in the synthesized samples (index $\mu$ on the plot) predetermined by the better solubility of alumina and silica in alkaline media and further crystallization of the obtained hydrogel in a determined zeolite phase. The presence of PHI in some of the samples does not influence the porosity of the FAZs. It was established that the chemical composition of the raw FA does not affect significantly the zeolitization process in the $\mathrm{SiO}_{2} / \mathrm{Al}_{2} \mathrm{O}_{3}$ range of 1.5-2.3, and the FAU structure is obtained by all of the investigated raw materials.

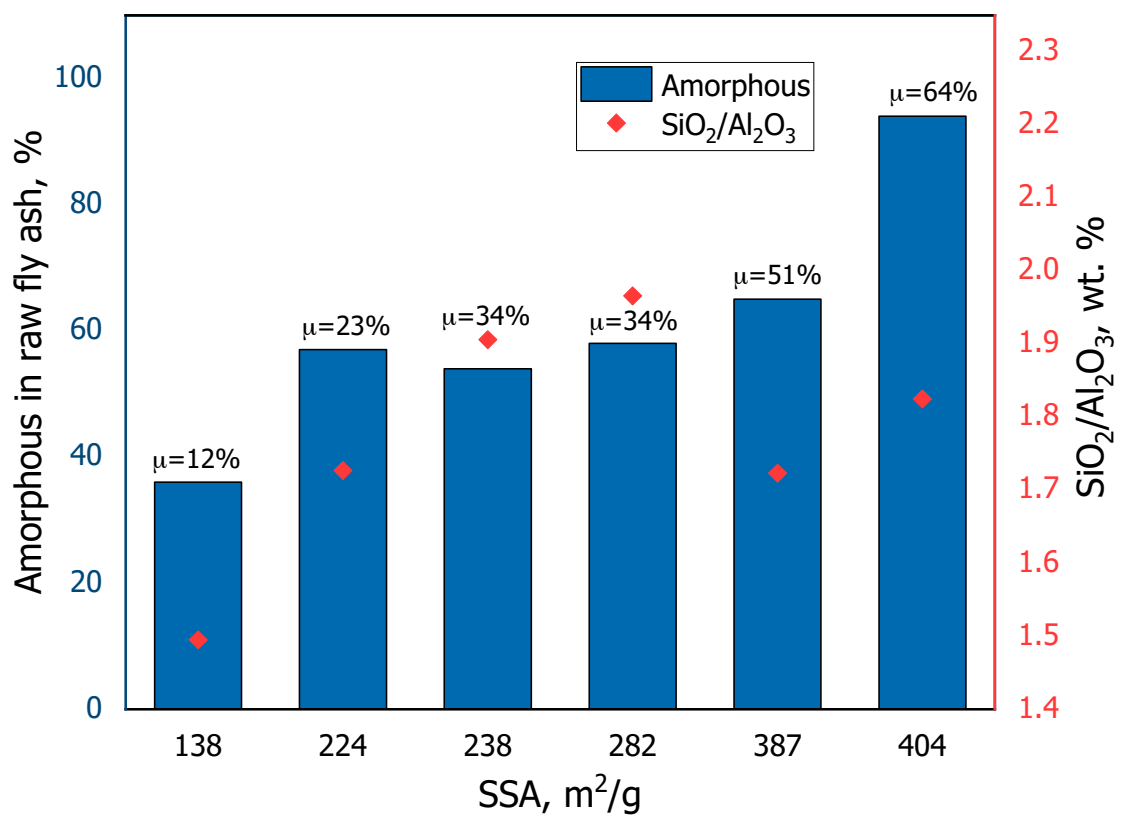

Figure 5. Dependences between surface properties of investigated samples and raw fly ash properties.

\subsection{Adsorption of Malachite Green from Coal Ash Zeolites}

The adsorption of MG onto the surface of the synthetic zeolites is investigated at $10 \mathrm{mg} / \mathrm{L}$ concentration of the stock solution by adding $3 \mathrm{~g} / \mathrm{L}$ of the zeolite products. The removal efficiency RE (\%) of coal fly ash zeolites toward MG at different times of analyses is calculated by the following equation:

$$
\operatorname{RE}(\%)=\left(\left(\mathrm{C}_{0}-\mathrm{C}_{\mathrm{e}}\right) / \mathrm{C}_{0}\right) \cdot 100
$$

where $C_{0}$ is the initial concentration of MG in the test solutions; $C_{e}$ is the measured equilibrium concentration of MG in the liquid phase after the adsorption, $\mathrm{mg} / \mathrm{L}$.

The results from the MG kinetic study on FAZs are plotted in Figure 6.

The experimental results were described applying the pseudo first- (Equation (2)) and second-order (Equation (3)) kinetic models. The linear forms of the model equations used are as follows:

$$
\begin{gathered}
-\ln \left(\mathrm{C}_{\mathrm{MG}, \tau} / \mathrm{C}_{\mathrm{MG}, 0}\right)=\mathrm{k}_{1} \tau \\
\tau / \mathrm{C}_{\mathrm{MG}, \tau}=1 /\left(\mathrm{k}_{2} \cdot \mathrm{C}_{\mathrm{MG}, 0}\right)+\tau / \mathrm{C}_{\mathrm{MG}, 0}
\end{gathered}
$$


where $k_{1}$ and $k_{2}$ are the reaction rate constants for the kinetic models of the pseudo first- and second-order, $\mathrm{min}^{-1}$ and $\mathrm{M}^{-1} \cdot \mathrm{min}^{-1}$, correspondingly; $\tau$ is the reaction time, min.
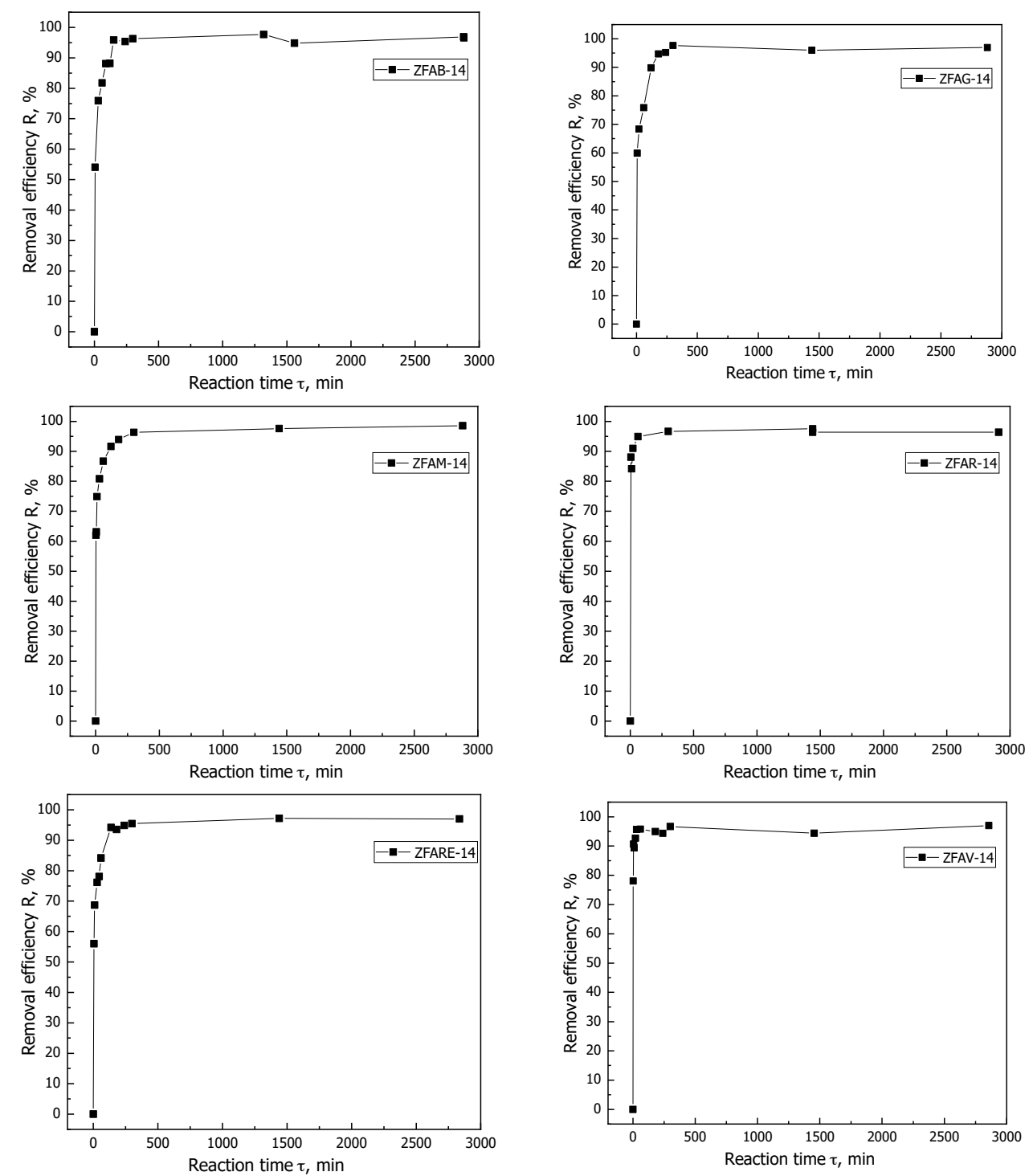

Figure 6. Adsorption kinetics of Malachite green onto the surface of synthetic fly ash zeolites obtained after 14 months of self-crystallization.

Linear plots of pseudo first- (PFO) and second- (PSO) order kinetic models are shown in Figure 7 together with the results from regression analyses. The PFO does not correlate to the experimental data, as R-Square varies in the range of $0.22-0.63$, while the PSO effectively describes the kinetics of the adsorption with R-Square of 0.999 for all samples.

The calculated rate constant $\mathrm{k}_{2}\left(\mathrm{M}^{-1} \cdot \mathrm{min}^{-1}\right)$ and half-life time $\tau_{1 / 2}\left(\mathrm{~min}^{-1}\right)$ from the PSO kinetics modelling and the obtained maximum removal efficiencies of FAZ toward MG are listed in Table 3. The fastest adsorption kinetics is calculated for the samples ZFAR-14 and ZFAV-14 but the highest removal efficiency is achieved at ZFAR-14. Although the investigated samples are characterized with surface areas varying in a wide range, all of them reach almost full remediation of the water solutions from MG. At these concentration levels of MG, the adsorption process probably takes place on the external surface of the ZFAs and the MG molecules do not penetrate into the pore volume composed of micro and mesopores. This is a prerequisite for the FAZs to have the capacity to remove completely even higher levels of this contaminant. 

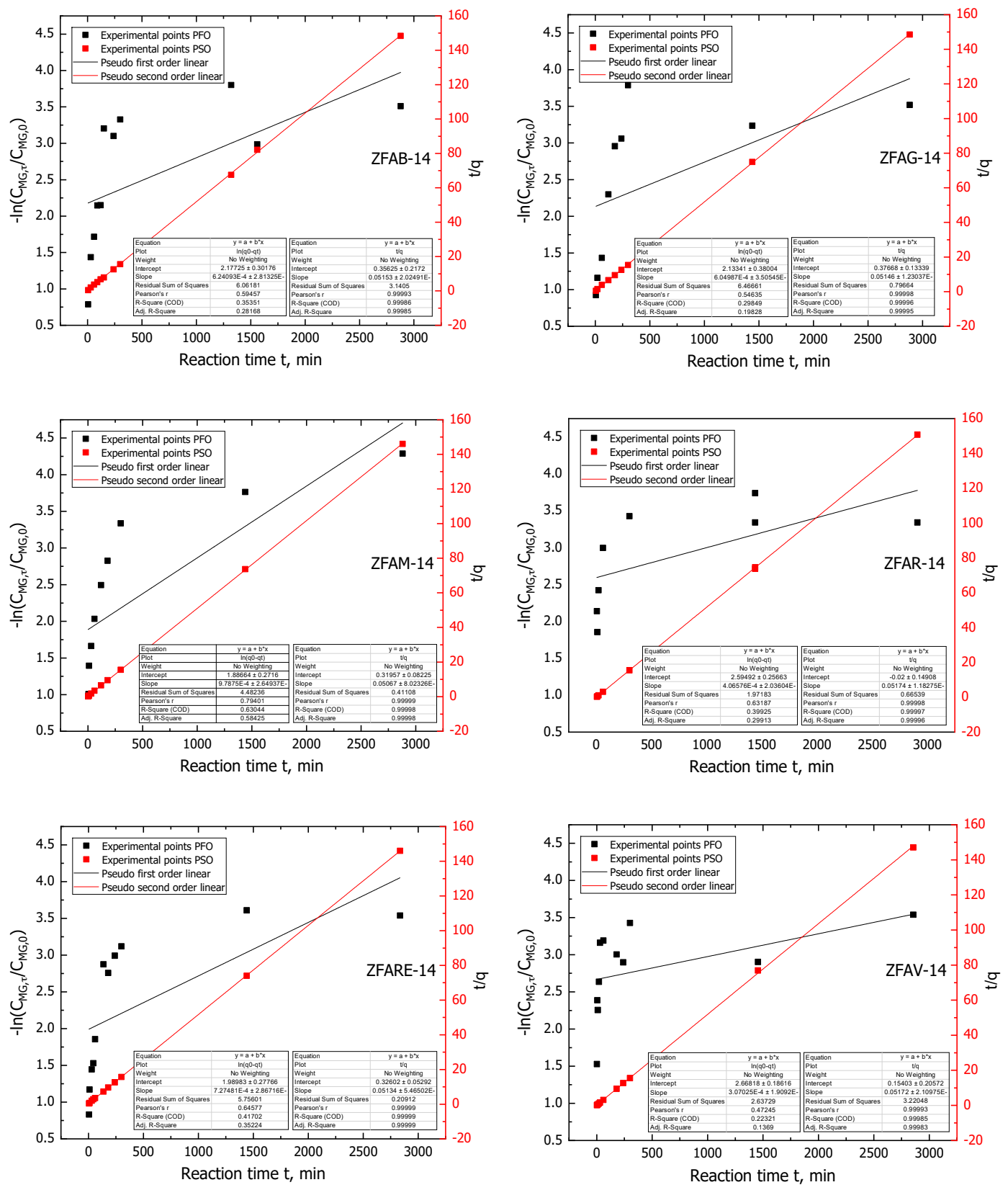

Figure 7. Regression analyses of the experimental data by pseudo first- (PFO) and second- (PSO) order kinetic models (linear plots).

Table 3. Parameters of pseudo-second-order kinetic model for adsorption of Malachite green onto fly ash zeolite surface and the obtained removal efficiencies.

\begin{tabular}{|c|c|c|c|c|c|c|c|}
\hline \multicolumn{2}{|c|}{ PSO } & ZFAB-14 & ZFAG-14 & ZFAM-14 & ZFAR-14 & ZFARE-14 & ZFAV-14 \\
\hline $\mathrm{k}_{2}$ & $\mathrm{M}^{-1} \cdot \min ^{-1}$ & 0.0075 & 0.0070 & 0.0080 & 0.0180 & 0.0081 & 0.0174 \\
\hline$\tau_{1 / 2}$ & $\min$ & 13.42 & 14.22 & 12.45 & 5.57 & 12.37 & 5.76 \\
\hline $\mathrm{RE}_{\max }$ & $\%$ & 96.6 & 97.0 & 98.6 & 97.5 & 97.0 & 97.0 \\
\hline
\end{tabular}

The study of the sorption kinetics of wastewater treatment is important to clarify the process mechanism, the rate of retention of contaminants, and the time for exhaustion of the sorbent capacity. These characteristics are important in the design of efficient sorption treatment plants for water treatment of specific pollutants. It was found that the pseudo-second-order model provides the best correlation to the adsorption kinetics of MG onto FA, which means that the rate-limiting stage 
is chemisorption involving valence forces by electronic sharing or exchange between sorbent and sorbate [41]. This is confirmed by the fact that no unambiguous tendency of increase in the adsorption rate constant with increase in the specific surface of coal ash zeolites is established. In a case that the adsorption process proceeds with diffusion control, then the surface characteristics of the adsorbent, such as particle size, specific surface area and pore diameter will be essential for the process kinetics, which is not observed for the present adsorption studies. It could be assumed that the chemisorption mechanism of MG onto FAZ is obeyed by the cationic behavior of this dye upon its dissolution into water. Cationic dyes carry positive charges in their molecules and dissociate into cations in the aqueous solutions [42]. In this case, an ion exchange process can occur between the mobile cations in the zeolite structure and the dye cations from the solution. Finally, it could be supposed that the rate of adsorption of MG on FAZ will initially be dominated by surface factors, and as the process progresses, the concentration and the distribution of the ion exchange sites in the zeolite framework will play a key role. Some studies reveal that the raw fly ash can also behave a high retention capacity for some pollutants, for example, toward anionic surfactants [43]. However, adsorbents based on zeolitized ash definitely have a number of advantages in water purification. Coal ash zeolites have a higher specific retention capacity per unit mass, which means less need for adsorbent to treat a unit volume of water. Another advantage is that zeolitized coal ash releases fewer impurities into the remediated water as compared to the parent ash, which is characterized by substantial leaching. The ability of coal zeolites to act as ion exchangers and adsorbents makes them applicable in the cleaning of industrial sludges, acid mine drainages, industrial, agricultural and domestic waters by a variety of techniques, such as filtration, coagulation and catalytic degradation of contaminants. Moreover, they can serve as permeable reactive barriers for remediation and barriers against infiltrations of toxic components into ground water.

\section{Conclusions}

The focus of this study is on the crystallization of zeolites from different coal fly ashes at ambient conditions. The obtained materials were investigated for two times of aging in regard to identify the phase composition and morphology of the final products. It was established that the self-crystallization process at low temperature ensures long-term controllable synthesis of zeolite FAU from FA of different coal types, at a wide range of $\mathrm{SiO}_{2} / \mathrm{Al}_{2} \mathrm{O}_{3}$ ratios, and varying extent of amorphization. It was also observed that the yield of the zeolite FAU is mainly favored by the higher amounts of the amorphous aluminosilicates in the raw material. The values of the experimentally determined specific surface area over $400 \mathrm{~m}^{2} / \mathrm{g}$ and the textural properties of the synthesized zeolites are beneficial for a wide range of possible applications. This synthesis approach is promising for large-scale waste utilization because of its simplicity, zero energy demands and low operational costs. It could be easily applied in the places of fly ash landfills and long-accumulated waste can be recovered. The quasi natural synthesis procedure would meet the environmental challenges of waste storage management, and in the same time would produce a valuable commercial product. In this study, one of the possible approaches for useful utilization of the coal fly zeolites obtained by different sources was investigated. The successful adsorption of malachite green was achieved with removal efficiency over $96 \%$. The experimental data were fitted to the second-order kinetic reaction model with high correlation.

Author Contributions: Conceptualization, D.Z.; methodology, D.Z., A.S. and V.S.; software, G.A., D.Z.; validation, V.S., A.S. and D.Z.; formal analysis, D.Z. and A.S.; investigation, A.S., V.S., D.Z. and S.B.; resources, S.B.; data curation, G.A., D.Z.; writing-original draft preparation, D.Z.; writing-review and editing, S.B, D.Z. and V.S.; visualization, D.Z., V.S. and A.S.; supervision, S.B. and A.S.; project administration, S.B.; funding acquisition, S.B. All authors have read and agreed to the published version of the manuscript.

Funding: This research and article processing charge were funded by National Science Fund, Ministry of Education and Science of R. Bulgaria under the Grant DN 17/18 (2017).

Acknowledgments: The authors express their gratitude to all colleagues from the Electron Microscopy Lab of Institute of Physical Chemistry at Bulgarian Academy of Sciences (IPC-BAS) for their technical assistance in the SEM and EDX analysis. 
Conflicts of Interest: The authors declare no conflict of interest.

\section{References}

1. IEA Statistics $2018 \mathrm{CO}_{2}$ Emissions from Fuel Combustion: Overview. Available online: https://www.iea.org/ subscribe-to-data-services/CO2-emissions-statistics (accessed on 21 November 2020).

2. Yang, H.; Xu, Z.; Fan, M.; Gupta, R.; Slimane, R.B.; Bland, A.E.; Wright, I. Progress in carbon dioxide separation and capture: A review. J. Environ. Sci. 2008, 20, 14-27. [CrossRef]

3. Król, A. The role of the silica fly ash. Sustain. Waste Manag. 2016, 10. [CrossRef]

4. Brook, B.W.; Alonso, A.; Meneley, D.A.; Misak, J.; Blees, T.; van Erp, J.B. Why nuclear energy is sustainable and has to be part of the energy mix. Sustain. Mater. Technol. 2014, 1, 8-16. [CrossRef]

5. Shukla, A.K.; Ahmad, Z.; Sharma, M.; Dwivedi, G.; Verma, T.N.; Jain, S.; Verma, P.; Zare, A. Advances of carbon capture and storage in coal-based power generating units in an Indian context. Energies 2020, $13,4124$. [CrossRef]

6. Zhang, Z.; Pan, S.-Y.; Li, H.; Cai, J.; Olabi, A.G.; Anthony, E.J.; Manovic, V. Recent advances in carbon dioxide utilization. Renew. Sustain. Energy Rev. 2020, 125, 109799. [CrossRef]

7. Stuardi, F.M.; MacPherson, F.; Leclaire, J. Integrated $\mathrm{CO}_{2}$ capture and utilization: A priority research direction. Curr. Opin. Green Sustain. Chem. 2019, 16, 71-76. [CrossRef]

8. Lee, B.J.; Lee, J.I.; Yun, S.Y.; Lim, C.; Park, Y. Economic evaluation of carbon capture and utilization applying the technology of mineral carbonation at coal-fired power plant. Sustainability 2020, 12, 6175. [CrossRef]

9. World Wide Coal Combustion Products Network (WWCCPN): Member information 2018/2019. Available online: https://wwccpn.com/ (accessed on 21 November 2020).

10. ASTM C618-17, Standard Specification for Coal Fly Ash and Raw or Calcined Natural Pozzolan for Use in Concrete; ASTM International: West Conshohocken, PA, USA, 2017.

11. Zgureva, D.; Boycheva, S.; Behunová, D.; Václavíková, M. Smart- And zero-energy utilization of coal ash from thermal power plants in the context of circular economy and related to soil recovery. J. Environ. Eng. 2020, 146, 04020081. [CrossRef]

12. Baek, C.; Seo, J.; Choi, M.; Cho, J.; Ahn, J.; Cho, K. Utilization of CFBC fly ash as a binder to produce in-furnace desulfurization sorbent. Sustainability 2018, 10, 4854. [CrossRef]

13. Podgorodetskii, G.S.; Gorbunov, V.B.; Agapov, E.A.; Erokhov, T.V.; Kozlova, O.N. Challenges and opportunities of utilization of ash and slag waste of TPP (thermal power plant). Part 1. Izv. Ferr. Metall. 2018, 61, 439-446. [CrossRef]

14. Bergk, K.H.; Porsch, M.; Wolf, F. Transformation of primary- and secondary raw materials in zeolite containing products. part I: Production of zeolite-A containing products from power plant fly ash. Chem. Tech. 1985, 37, 253-256.

15. Querol, X.; Moreno, N.; Alastuey, A.; Juan, R.; Andrés, J.M.; López-Soler, A.; Ayora, C.; Medinaceli, A.; Valero, A. Synthesis of high ion exchange zeolites from coal fly ash. Geol. Acta 2007, 5, 49-57.

16. Bukhari, S.; Rohani, S. Continuous flow synthesis of zeolite-A from coal fly ash utilizing microwave irradiation with recycled liquid stream. Mater. Eng. Sci. Div. 2016-Core Program. Area 2016 AIChE Annu. Meet. 2016, 2, 558-565.

17. Adamczyk, Z.; Białecka, B. Hydrothermal synthesis of zeolites from polish coal fly ash. Pol. J. Environ. Stud. 2005, 14, 713-719.

18. Fukui, K.; Nishimoto, T.; Takiguchi, M.; Yoshida, H. Effects of $\mathrm{NaOH}$ concentration on zeolite synthesis from fly ash with a hydrothermal treatment method. KONA Powder Part. J. 2006, 24, 183-191. [CrossRef]

19. Inada, M.; Tsujimoto, H.; Eguchi, Y.; Enomoto, N.; Hojo, J. Microwave-assisted zeolite synthesis from coal fly ash in hydrothermal process. Fuel 2005, 84, 1482-1486. [CrossRef]

20. Molina, A.; Poole, C. A comparative study using two methods to produce zeolites from fly ash. Miner. Eng. 2004, 17, 167-173. [CrossRef]

21. Fukui, K.; Arai, K.; Kanayama, K.; Yoshida, H. Phillipsite synthesis from fly ash prepared by hydrothermal treatment with microwave heating. Adv. Powder Technol. 2006, 17, 369-382. [CrossRef]

22. Shoumkova, A.; Stoyanova, V. Zeolites formation by hydrothermal alkali activation of coal fly ash from thermal power station "Maritsa 3", Bulgaria. Fuel 2013, 103, 533-541. [CrossRef] 
23. Querol, X.; Moreno, N.; Umaa, J.C.; Alastuey, A.; Hernández, E.; López-Soler, A.; Plana, F. Synthesis of zeolites from coal fly ash: An overview. Int. J. Coal Geol. 2002, 50, 413-423. [CrossRef]

24. Murayama, N.; Yamamoto, H.; Shibata, J. Mechanism of zeolite synthesis from coal fly ash by alkali hydrothermal reaction. Int. J. Miner. Process. 2002, 64, 1-17. [CrossRef]

25. Ferret, L.; Fernandes, I.D.; Khahl, C.A.; Endres, J.C.T.; Maegawa, A. Zeolitification of ashes obtained from the combustion of southern's Brazil candiota coal. In Proceedings of the International ash Utilization Symposium, Lexington, KY, USA, 18-20 October 1999.

26. Singer, A.; Berkgaut, V. Cation exchange properties of hydrothermally treated coal fly ash. Environ. Sci. Technol. 1995, 29, 1748-1753. [CrossRef] [PubMed]

27. Shigemoto, N.; Hayashi, H.; Miyaura, K. Selective formation of Na-X zeolite from coal fly ash by fusion with sodium hydroxide prior to hydrothermal reaction. J. Mater. Sci. 1993, 28, 4781-4786. [CrossRef]

28. Shigemoto, N.; Shirakami, K.; Hirano, S.; Hayashi, H. Preparation and characterization of zeolites from coal ash. Nippon Kagaku Kaishi 1992, 5, 484-492. [CrossRef]

29. Jha, V.K.; Matsuda, M.; Miyake, M. Resource recovery from coal fly ash waste: An overview study. J Ceram. Soc. Jpn. 2008, 116, 167-175.

30. Fotovat, F.; Kazemian, H.; Kazemeini, M. Synthesis of Na-A and faujasitic zeolites from high silicon fly ash. Mater. Res. Bull. 2009, 44, 913-917. [CrossRef]

31. Jha, V.K.; Matsuda, M.; Miyake, M. Sorption properties of the activated carbon-zeolite composite prepared from coal fly ash for $\mathrm{Ni}^{2+}, \mathrm{Cu}^{2+}, \mathrm{Cd}^{2+}$ and $\mathrm{Pb}^{2+}$. J. Hazard. Mater. 2008, 160, 148-153. [CrossRef]

32. Klamrassamee, T.; Pavasant, P.; Laosiripojana, N. Synthesis of zeolite from coal fly ash: Its application as water sorbent. Eng. J. 2010, 14, 37-44. [CrossRef]

33. Shoumkova, A. Zeolites for water and wastewater treatment: An overview. Res. Bull. Aust. Inst. High Energetic Mater. Spec. Issue Glob. Fresh Water Short. 2011, 2, 10-70.

34. Boycheva, S.; Zgureva, D.; Miteva, S.; Marinov, I.; Behunová, D.M.; Trendafilova, I.; Popova, M.; Václaviková, M. Studies on the potential of nonmodified and metal oxide-modified coal fly ash zeolites for adsorption of heavy metals and catalytic degradation of organics for waste water recovery. Processes 2020, 8, 778. [CrossRef]

35. Srivastava, S.; Sinha, R.; Roy, D. Toxicological effects of malachite green. Aquat. Toxicol. 2004, 66, 319-329. [CrossRef] [PubMed]

36. Shoumkova, A.; Stoyanova, V.; Tsacheva, T. Preliminary study on the zeolitization of coal fly ashes from six Bulgarian thermal power plants. SEM-EDX analyses. Compt. Rend. L'Acad. Bulg. Sci. 2011, 64, 937-944.

37. Pascova, R.; Stoyanova, V.; Shoumkova, A. Room temperature zeolitization of boiler slag from a Bulgarian thermal power plant. J. Serb. Chem. Soc. 2017, 82, 227-240. [CrossRef]

38. ISO 9277:2010 Determination of the Specific Surface Area of Solids by Gas Adsorption-BET Method; International Organization for Standardization: Geneva, Switzerland, 2010.

39. Wang, Z.; Jiang, X.; Pan, M.; Shi, Y. Nano-scale pore structure and its multi-fractal characteristics of tight sandstone by $\mathrm{N}_{2}$ adsorption/desorption analyses: A case study of shihezi formation from the sulige gas field, Ordos Basin, China. Minerals 2020, 10, 377. [CrossRef]

40. Majchrzak-Kucęba, I. A simple thermogravimetric method for the evaluation of the degree of fly ash conversion into zeolite material. J. Porous Mater. 2013, 20, 407-415. [CrossRef]

41. Ho, Y.S.; McKay, G. Pseudo-second order model for sorption processes. Process Biochem. 1999, 34, 451-465.

42. Raval, N.P.; Shah, P.U.; Shah, N.K. Malachite green "a cationic dye" and its removal from aqueous solution by adsorption. Appl. Water Sci. 2017, 7, 3407-3445. [CrossRef]

43. Zanoletti, A.; Federici, S.; Borgese, L.; Bergese, P.; Ferroni, M.; Depero, L.E.; Bontempi, E. Embodied energy as key parameter for sustainable materials selection: The case of reusing coal fly ash for removing anionic surfactants. J. Clean. Prod. 2017, 141, 230-236. [CrossRef]

Publisher's Note: MDPI stays neutral with regard to jurisdictional claims in published maps and institutional affiliations. 